\title{
Transient Analysis of Electric Energy Distribution Systems with Distributed Generators during Contingencies
}

\author{
Wandry Rodrigues Faria ${ }^{1}$, Marcelo Escobar de Oliveira ${ }^{2}$, Jonas Villela de Souza ${ }^{1}$, Luis Gustavo Wesz \\ da Silva ${ }^{2}$ and Ghunter Paulo Viajante ${ }^{2}$ \\ ${ }^{1}$ Department of Electrical Engineering \\ São Carlos School of Engineering, University of São Paulo - USP \\ São Carlos - São Paulo, Brazil \\ Phone/Fax number: +005516 33738152, e-mail: wandry@usp.br, jonas.villela@usp.br \\ ${ }^{2}$ Núcleo de Pesquisas em Sistemas de Energia - NuPSE \\ Federal Institute of Education, Science and Technology of Goiás - IFG \\ Itumbiara - Goiás, Brazil \\ Phone/Fax number: +0055 64 21035600, e-mail: marcelo.oliveira@ifg.edu.br
}

\begin{abstract}
This paper analyzes the static and dynamic impact of the massive insertion of distributed generators into the distribution systems. For this study the IEEE 33-bus test system is represented on the Simulight platform. Three short-circuit situations are simulated. The results obtained in the simulations are compared with the operating ranges described in module 8 of the Electric Power Distribution Procedures in the Brazilian National Electric System. The comparison between the dynamic regimes of the test system with and without distributed generators points out the greater stability sensitivity of the synchronous generators used in industrial cogeneration projects and reaffirms the need to perform contingency simulations to determine the protection parameters of the installed generators.
\end{abstract}

Keywords. Contigencies, Distributed Generation, Electric Power Distribution Systems, Stability Study.

\section{Introduction}

Distribution Systems Networks (DS) are characteristically composed by passive elements, that is, the loads do not inject power into the network, only absorb it. Based on this, another classic concept of distribution systems emerges: the unidirectional current flow from the substation (SE) towards the consumers (loads). However, this scenario has been intensively modified in the last decades, with the insertion of generators of electric energy in the points of consumption, denominated of Distributed Generators (DG). With the installation of DG, consumers will be able to inject current into the system, which raises the concern of the effects of the so-called "reverse flow of power" from the network to the SE.

The circulation of electric current in the reverse direction in stretches of the distribution system is an operation situation not foreseen in the design stage of the network in the past. In the design of the networks, the topology of the operation of the lines is defined in order to provide adequate electricity supply to those established by the regulatory agencies. Inserting DG into a projected network without predicting current flow in both directions without a review of its system impact can increase technical power losses and put consumers' voltage levels in inappropriate bands. Added to the question of variation of the optimum operating topology of the DS, some precautions are needed to be taken in the scope of system protection. In general, the DS do not use relays with directional sensitization, since this type of protection is applied in systems with supply in more than one direction or ring topology [1]. With the presence of DG the direction of the power flow must be taken into account for the protection or not. Still in the system protection sphere, in the event of a short circuit in the distribution network, the distributed generators will supply current to the fault, which means that the short circuit levels are potentiated and should be reevaluated.

Relying on these and other premises, many researchers in the last decade have addressed DG impacts in the distribution and transmission systems. Among the studies that were developed analyzing distribution networks, a large part exposed the reflexes of the distributed generation in the steady state voltage levels, or static analysis. However, there is a gap with respect to the dynamic behavior of DG systems analysis, in other words, checking the transient angular, frequency and voltage responses of a network with DG throughout a contingency situation.

The purpose of this paper is to contribute to the aforementioned reduction of the hiatus from the creation of computational tools capable of providing static and dynamic analyzes of electric energy distribution systems considering the insertion of distributed generators in electric energy distribution networks. In this work an analysis is presented in a distribution system considering a fault in one of the points of the network. In this analysis, angular, frequency and voltage stability are taken into account. 


\section{Distribution Systems of Electric Energy in Dynamic Regime}

The first instants of the response of an Electric Power System (PS) to a stepped input voltage or to a balance variation between generation and consumption quantities cannot be predicted using frequency-based methods. Thus, the power flow routine used for steady state calculations is ineffective in dynamic regime, that is, during the period of time when the PS has not yet reached operational equilibrium.

The duration of the dynamic regime is proportional to the size of the system and the operating conditions to which the PS is subjected. It is valid to show that, for some situations, the system is not able to reach the static regime. Thus, the DS when in a dynamic regime can be categorized as stable or unstable, and the permanent regime is reached only by stable systems. In the study of system stability all the dynamic electrical and mechanical characteristics of generating and consuming units - such as moment of inertia of rotating machines, inductances and capacitances of lines, loads, transformers, reactive compensators and generators must be taken into account. According to the methodology presented in [2], the stability of a system or element of the system is divided into three parts:

- Angular Stability;

- Frequency Stability;

- Stability of the Voltage Magnitude.

The consideration of the use of synchronous machines as a distributed generator in industries, strengthened by the high contribution of the industries to the power generated in a decentralized way, bases the approach of the angular stability in DS presented in this work.

\section{A. Stability of the Voltage Magnitude}

Voltage variations are caused by unbalances between the reactive power generated and consumed in an electrical system. In static regime the generation and consumption are balanced, for a case of dynamic voltage regime happens it is necessary to vary the operating conditions of the system the loss of a large block of loads that demand remarkable levels of reactive power or loss of the bank of capacitors or loss of shunt reactors of a line.

The great imbalances of the reactive power reflect in greater amplitudes of the variations in the voltage, however the duration of the phenomenon does not depend on the magnitude of the disturbance. Dynamic time can vary with the response speed of the voltage controllers of the synchronous machines excitation, response time for insertion or removal of reactive compensators or the time to cut loads.

The Module 8 of the Distribution Procedures (PRODIST), elaborated by the Brazilian Electricity Regulatory Agency [3] - addresses voltage variations - which are considered dynamic if they return to acceptable operating ranges for the permanent regime, presented in Table 1 , up to 3 minutes. If the contingency lasts more than 3 minutes, it is considered an operation of permanent regime. Voltage variations are considered only in cases where the magnitude of the voltage does not return to the nominal ranges for at least 1 cycle, in case of lifting or sinking, or 3 seconds in case of interruption. Events less than these are considered to be voltage fluctuations and are not addressed in this paper. Table I, adapted from PRODIST [3], presents the classification of voltage variations in dynamic regime.

Table I. - Voltage Contingencies Classification [3]

\begin{tabular}{|c|c|c|c|}
\hline $\begin{array}{l}\text { Contingency } \\
\text { Classification }\end{array}$ & Denomination & Duration & Magnitude \\
\hline \multirow{3}{*}{$\begin{array}{c}\text { Instantaneous } \\
\text { Voltage } \\
\text { Variation }\end{array}$} & $\begin{array}{l}\text { Instantaneous } \\
\text { Interruption }\end{array}$ & $t \leq 3 s$ & $\begin{array}{l}V_{\text {measured }} \\
\leq \mathbf{0}, 1 \mathrm{pu}\end{array}$ \\
\hline & $\begin{array}{c}\text { Instantaneous } \\
\text { Attenuation }\end{array}$ & $t \leq 3 s$ & $\begin{array}{l}0,1 \\
<V_{\text {measured }} \\
\leq 0,9 \mathrm{pu} \\
\end{array}$ \\
\hline & $\begin{array}{c}\text { Instantaneous } \\
\text { Elevation }\end{array}$ & $t \leq 3 s$ & $\begin{array}{l}V_{\text {measured }} \\
\geq 1,1 \mathrm{pu}\end{array}$ \\
\hline \multirow{3}{*}{$\begin{array}{l}\text { Momentary } \\
\text { Voltage } \\
\text { Variation }\end{array}$} & $\begin{array}{l}\text { Momentary } \\
\text { Interruption }\end{array}$ & $\begin{array}{l}3 s<t \\
<3 \min \\
\end{array}$ & $\begin{array}{l}V_{\text {measured }} \\
\leq \mathbf{0 , 1} p u\end{array}$ \\
\hline & $\begin{array}{l}\text { Momentary } \\
\text { Attenuation }\end{array}$ & $\begin{array}{l}3 s<t \\
<3 \text { min } \\
\end{array}$ & $\begin{array}{l}0,1 \\
<V_{\text {measured }} \\
\leq 0,9 \mathrm{pu} \\
\end{array}$ \\
\hline & $\begin{array}{l}\text { Momentary } \\
\text { Elevation }\end{array}$ & $\begin{array}{l}3 s<t \\
<3 \min \end{array}$ & $\begin{array}{l}V_{\text {measured }} \\
\geq 1,1 \mathrm{pu}\end{array}$ \\
\hline
\end{tabular}

It is important to note that voltage variations assume a range of magnitudes, some cases are more serious than others. Thus, an impact factor of the dynamism of the tensions in the system is calculated through the classification of the voltage sags, elevations and interruptions in areas of sensitivity as shown on Table II, being the region $\mathrm{A}$ the best and the region $\mathrm{H}$ the worst case.

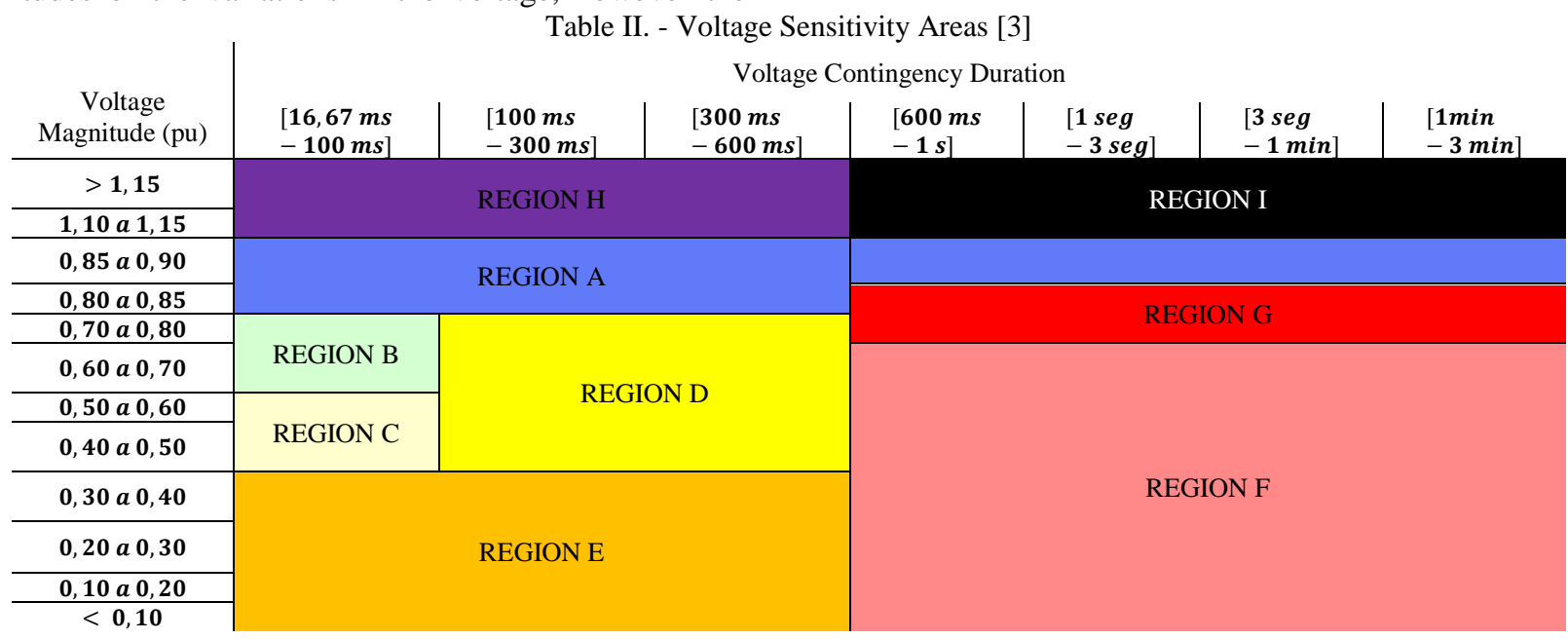




\section{B. Frequency Stability}

The imbalances between active power generated and demanded in the PS, when small, are suppressed by the available spinning reserve in the system. In Brazil the rotating reserve is composed of a set of synchronous machines - at least one in each hydroelectric plant - already synchronized to the system, but with zero power supply and consumption. In the event of a disturbance where a block of charges or sudden generation is lost or added, the frequency suffers a deviation from its fundamental value - in the case of the increase of charge the frequency falls and, otherwise, the frequency tends to rise. Frequency variation tends to change the speed of rotation of the generating units, however, the speed controllers increase or reduce the volume of water in the turbine by opening or closing the distributors, increasing or decreasing the mechanical torque and, consequently, the electrical power of the machine.

The application of an interconnected system like the Brazilian one causes that the capacity of absorption of charges by the system of generation increases. Each generating unit has a contribution proportional to its inertia value, since a machine with more inertia offers more resistance to the variation of the speed of rotation and, consequently, of frequency. On the other hand, since the inertia characteristics are also summed, the time constants for systemic generation adjustments are high. In practical terms, in the event of a disturbance large enough to cause a sudden change in frequency, the equilibrium is reached more quickly in smaller systems.

As far as distribution systems or handlers operating on the island are concerned, as it is a possibility for DS with proper distributed generation inserted, the concern with frequency disturbances becomes greater. In large frequency disturbances, although the response of the rotating reserve is instantaneous, it is necessary to intervene by the Brazilian National System Operator (ONS), whose function is to contact the generating and transmitting companies connected to the interconnected system and to inform management guidelines, equipment and generation variations to achieve the static regime. In the case of the islands, an organ with a systemic vision such as ONS may not exist and the time of exposure to extreme frequencies can be extended. In addition, the absence of a robust spinning reserve can make frequency events more frequent. Module 8 of PRODIST (2018) also addresses the dynamic regime of the electric frequency and the limitations were transcribed on Table III.

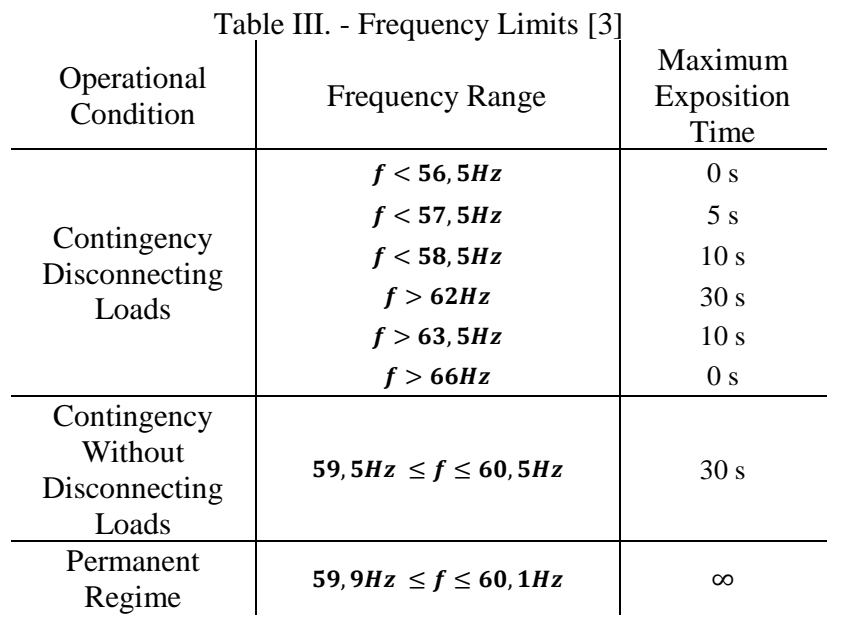

As indicated previously and ratified by Table III, in some perturbations it is necessary to cut loads to enable the recomposition of the equilibrium of the system's powers. According to [3], for disturbances where the frequency is contained in the range between $59.5 \mathrm{~Hz}$ and $60.5 \mathrm{~Hz}$ with a duration of up to 30 seconds, the cut of the load is not necessary; by means of non-compliance with any of the premises, there must necessarily be a cut of loads with possible sequential shutdowns in order to maintain the frequency in the bands and time limits determined by National Electric Energy Agency (ANEEL).

In this work, failure situations are applied in DS with DG and the frequency values in several buses are verified. Thus, it is possible to determine, in accordance with the limits indicated in PRODIST, in which cases it is necessary to interrupt the supply of electricity to some consumers.

\section{Angular Stability}

The angular stability is related to the balance between the mechanical and electromagnetic conjugates of the synchronous machines. The synchronous machines, in permanent regime, have equal electrical and mechanical power, nevertheless, before contingencies where there is the variation of one of the two quantities the machine enters in dynamic regime. If the disturbance results in instability of the synchronous machine, the generator loses synchronism with the other alternators of the interconnected system. From the study of the rotor stability, it is possible to determine the degree of robustness of the PS by disturbances - short circuits, losses of loads and generation, loss of lines - and, thus, to define the guidelines of expansion, the speed of the performance of the protection systems and determine the equipment to be inserted into the system.

The synchronous machines offer resistance to rotor speed change. Before a variation of the operating point of the PS, in the rotor of the synchronous machine, a torque on the opposite direction of the variation that forces the generator to maintain itself in the synchronous speed appears. However, in some cases of major disturbances the machine tends to move further away from the initial load angle, and if it is not switched off, it eventually loses sync with the PS. A system is considered to be stable from the angular point of view when, after a disturbance, the variation of the load angle is damped and the oscillations of the rotor deviations of the machines cease. Figure 6 shows the angular comparison between two systems: one stable and one unstable.

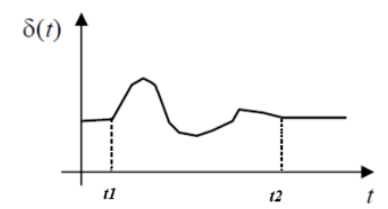

(A)

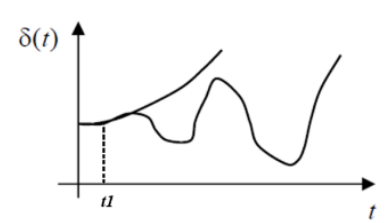

(B)
Fig. 1. Representation of Angular Stability. (A) Stable System. (B) Unstable System

Figure 1a shows a system that undergoes a variation of the load angle $(\delta)$ at time $t 1$, but after changes in the angle between the times $\mathrm{t} 1$ and $\mathrm{t} 2$, the system becomes constant 
in the time domain. This characteristic is not verified in the graphs of Figure 1.b, in it, after the disturbance at $\mathrm{t} 1$ the system does not have its angular variations attenuated and reaches the instability.

Angular stability is approached in different ways and various forms of calculation are consolidated in the literature [4]. In these analyzes one of the techniques used is to apply the equal area method, which is a graphical tool presented in [2] that allows the understanding of dynamism in a facilitated way. Figure 2 shows the application of the criterion of equal areas in a situation of variation of the equilibrium point of a synchronous machine.

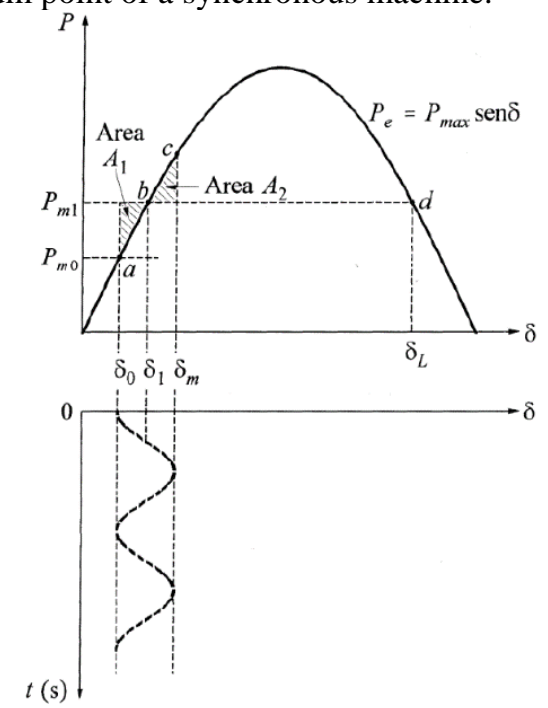

Fig. 2. Angular Stability by the Equal Areas Method [2]

Figure 2 shows a machine operating initially with a mechanical power $\mathrm{P}_{\mathrm{m} 0}$ and an electric power proportional to $\sin \left(\delta_{0}\right)$. In the occurrence of an increase of the mechanical torque the mechanical power was raised to $\mathrm{P}_{\mathrm{m} 1}$ and it is possible to check the oscillation of the load angle $(\delta)$ over time. The area under the mechanical power value $\left(A_{1}\right)$ is the acceleration torque of the machine while the area on the curve $\left(A_{2}\right)$ represents the deceleration of the rotor. The method of equal areas determines that the system is stable if the total acceleration of the machine is zero, that is, if the areas $A_{1}$ and $A_{2}$ are equal - the mathematical proof of the statement is presented in [5].

The equal area method has a limited application in systems containing only one machine connected to an infinite bus or representation of the interaction between two synchronous machines. The SIN or a DS with multiple distributed generators cannot be solved using the methodology presented in [2]. In [4] tools are presented to study angular stability in multi-machine systems; the software Simulight will be used in this work.

\section{Base Network Modeling}

Simulations of the various operating situations are performed in the 33-Bus IEEE test distribution system, available in [6]. With a rated voltage of $12.66 \mathrm{kV}$, it demands a power of $3715 \mathrm{~kW}$ with an inductive power factor of 0.94 .

In situations where there is DG, the connection between each generator and the network is made through a transformer with the characteristics described in Table IV.
Table IV. - Distributed Generator's Transformer Data

\begin{tabular}{cc} 
Nominal Power & $20 \mathrm{MVA}$ \\
\hline Voltage & $0,38 / 12,66 \mathrm{kV}$ \\
\hline $\mathrm{R} \%$ & 0 \\
\hline $\mathrm{X} \%$ & 10
\end{tabular}

This work assumes the insertion of distributed generators considering the application of synchronous machines in the process of electromechanical energy conversion. The choice of machine type is given for two reasons:

Angular stability study is interesting only for synchronous machines;

In industrial cogeneration projects, which represent the largest portion of the distributed generation of a DS, the use of the synchronous machine predominates.

The distributed generators used in this work have the characteristics in static regime described in Table V.

\begin{tabular}{cc|cc|cc}
\multicolumn{6}{c}{ Table V. - Distributed Generator Data } \\
$\begin{array}{c}\text { Nominal } \\
\text { Power }\end{array}$ & $\begin{array}{c}12,5 \\
\text { MVA }\end{array}$ & Pmin & $0 \mathrm{~W}$ & Qmin & $\begin{array}{c}-12,5 \\
\text { MVAR }\end{array}$ \\
\hline Voltage & $0,38 \mathrm{kV}$ & Pmax & $\begin{array}{c}12,5 \\
\text { MW }\end{array}$ & Qmax & $\begin{array}{c}12,5 \\
\text { MVAR }\end{array}$
\end{tabular}

It is important to highlight that the points where the distributed generators are allocated are defined as nontensioned buses - PQ buses.

The data used to calculate the dynamic response of the distributed generators are inserted directly into the software used for the analysis, through the graphical interface of the program. The dynamic data of the distributed generator used to design the machine on the Simulink platform are presented in [7] and in Tables VI and VII.

Table VI. Distributed Generator Dynamic Data [7]

$$
\begin{array}{c|c|c}
\mathrm{X}_{\mathrm{d}}=2.06 & \mathrm{X}_{\mathrm{d}}=0.398 & \mathrm{X}^{\prime}{ }_{\mathrm{d}}=0.254 \\
\mathrm{X}_{\mathrm{q}}=2.50 & \mathrm{X}_{\mathrm{q}}=0.30 & \\
\mathrm{X}_{\mathrm{l}}=0.10 & \mathrm{R}_{\mathrm{a}}=0 \\
\mathrm{~T}{ }_{\mathrm{d}}=7.80 & \mathrm{~T},{ }_{\mathrm{d}}=0.066 \\
\mathrm{~T}{ }_{\mathrm{q}}=3.00 & \mathrm{~T},{ }_{\mathrm{q}}=0.075 \\
\mathrm{H}=1.00 & \mathrm{D}=0 & \\
& \text { Sbase }=10 \mathrm{MVA}
\end{array}
$$

Table VII. - Distributed Generator Regulators Data [7]

\begin{tabular}{c|c} 
Voltage & Velocity \\
Regulator & Regulator \\
\hline $\mathrm{K}_{\mathrm{a}}=1.50$ & $\mathrm{R}_{\mathrm{v}}=0.05$ \\
$\mathrm{~T}_{\mathrm{a}}=0.15$ & $\mathrm{~T}_{\mathrm{v} 1}=0.05$ \\
& $\mathrm{~T}_{\mathrm{t} 1}=1.50$ \\
& $\mathrm{~T}_{\mathrm{t} 2}=5.00$ \\
& $\mathrm{D}_{\text {turb }}=0$
\end{tabular}

\section{Results of Dynamic Regime Analysis}

For the dynamical regime analysis, a considerable contribution of distributed generation was considered in the system, being 10 generators. Angular, voltage and frequency stability were analyzed by short-circuit simulation at different points in the network. Below we present the results considering the short circuit in bus 3 , which is near to the substation. 
Figure 3 shows the single-line diagram of the scenario system described above with representation of the point of failure of the contingency situation.

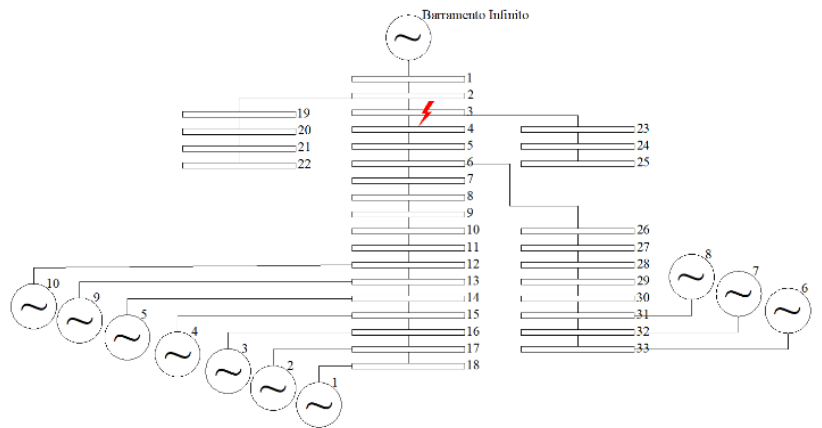

Fig.3. Test System with Contingency

The distributed generators were simulated considering that all have the same share of participation in the total power of the system. For all cases of multiple points with distributed generators the insertion points were maintained.

The degree of penetration is adopted $25 \%$ because this percentage of distributed generation the system presents tension in all buses within the proper range - for a degree of penetration $50 \%$ the voltage levels approximate to $1.05 \mathrm{pu}$ which means that any elevation of voltage may cause harmful to the equipment of the network. The network is also powered by an infinite bus.

The first contingency simulation considers that the fault short circuit in bus 5 - is eliminated in $100 \mathrm{~ms}$. However, as shown in Figure 4, the distributed generators lose angular stability. For this reason, the fault correction time has been reduced to $80 \mathrm{~ms}$ and the frequency, angle and voltage responses obtained for the generators are shown in Figures 5,6 and 7 .

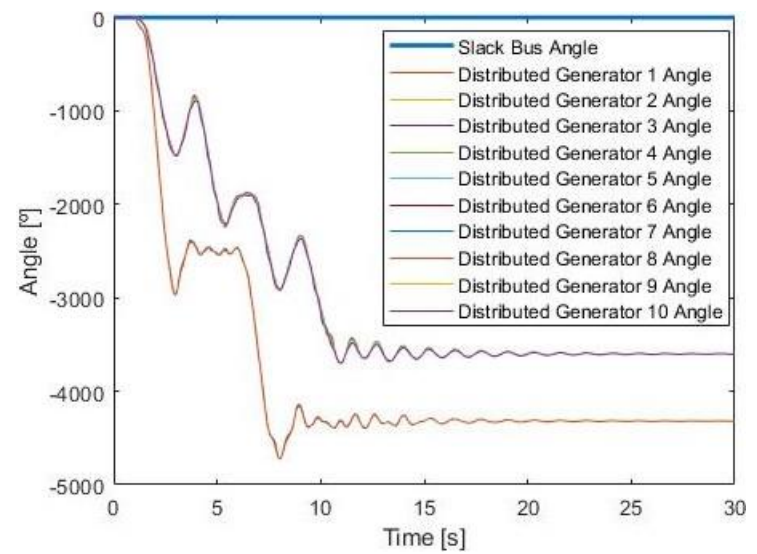

Fig. 4. Distributed Generators' Angular Stability Evaluation for Fault Removal at $100 \mathrm{~ms}$

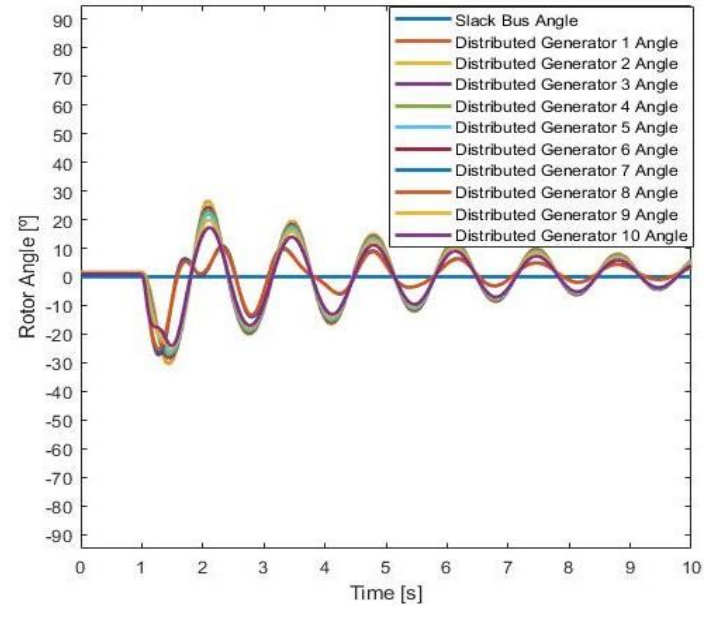

Fig. 5. Distributed Generators' Angular Stability Evaluation for Fault Removal at $80 \mathrm{~ms}$

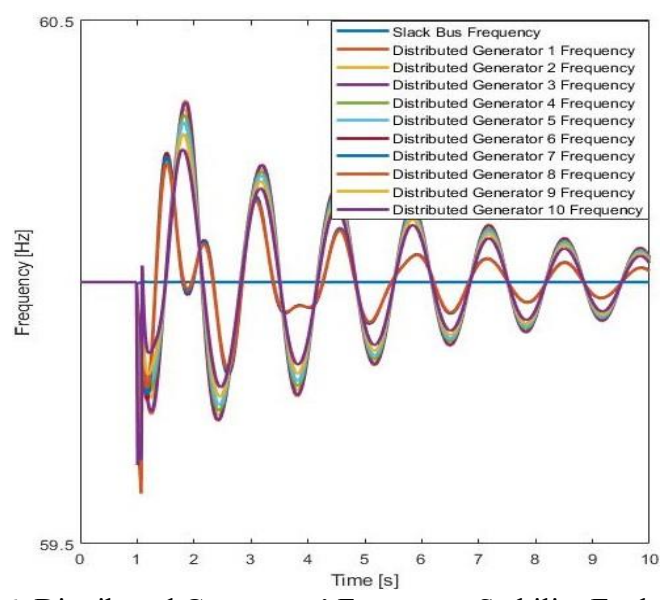

Fig. 6. Distributed Generators' Frequency Stability Evaluation for Fault Removal at $80 \mathrm{~ms}$

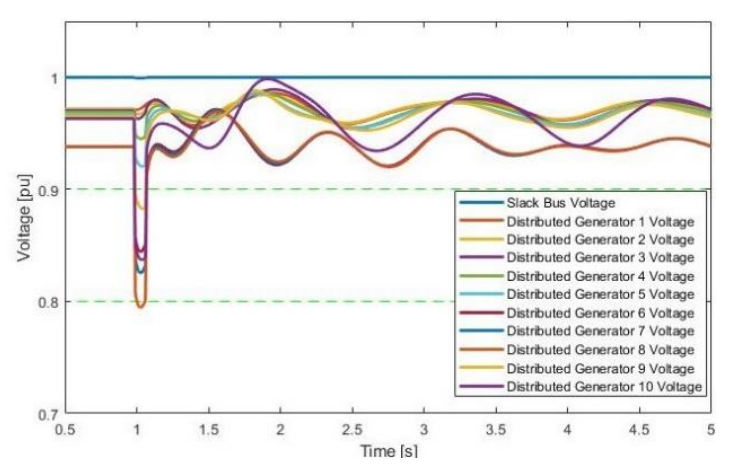

Fig. 7. Distributed Generators' Voltage Stability Evaluation for Fault Removal at $100 \mathrm{~ms}$

In situations of contingency, a system with multiple sources of power presents discrepancy between the waveforms of the electric quantities in the consumer buses in relation to those observed in the infinite bus. For this reason, the dynamic regimes are presented in five points of the system: bus 3 , bus 8 , bus 22 , bus 25 and bus 29 according to Figures 8 and 9 . 


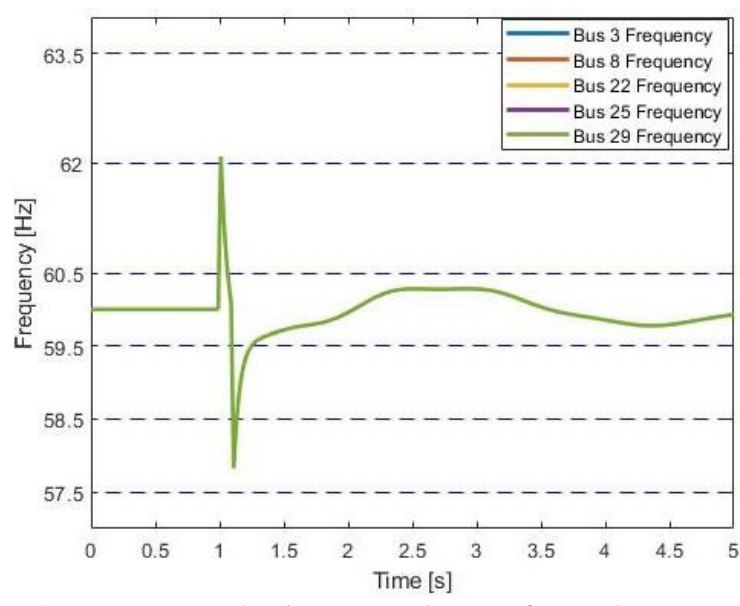

Fig. 8. Frequency Behavior on Load Buses for Fault Removal at $80 \mathrm{~ms}$



Fig. 9. Voltage Behavior on Load Buses for Fault Removal at 80 $\mathrm{ms}$

The transient responses of the system to the fault in bus 3 highlight positive and negative points of the DG insertion. On the one hand, most consumer buses continue to be fed even in a situation of contingency. On the other hand, it is crucial to verify the speed of action of the protection elements to avoid the loss of synchronism - Figure 5 - in case of use of synchronous machines in cogeneration plants. In addition, frequency transients appear with amplitude proportional to the lost power of the consumer bus - Figure 9 shows frequency variations for bus 25 that demand the disconnection of loads, according to [3].

\section{Conclusions}

This work investigated possible impacts of the insertion of distributed generation to the electric power distribution system from the transient point of view - considering the dynamism of synchronous machines. The IEEE 33-bus test system was submitted to several operating situations and, for each operational topology, three contingency events were simulated. The transient responses of the operating scenarios were analyzed and compared by the fault situations considering the variation of the degree of penetration of the distributed generation.

The study of the stability of the DS considering the insertion of DG allows also determining the minimum speed of performance of the protection of the distributed generators to avoid the loss of synchronism in situations of network failure.

The presented tool can be applied in the project of insertion of decentralized generation enterprises based on electromechanical energy conversion through synchronous machines to verify contingency situations and maximum forecast of the time for the protection of the generator.

\section{References}

[1] A. G. FERRARO, M. ARTICO, and B. A. BIANCO, "Proteção de sistemas elétricos de potência com ênfase em linhas de transmissão," 2013.

[2] P. Kundur, Power System Stability and Control. McGraw-Hill Professional, 1994.

[3] PRODIST, "Procedimentos de Distribuição de Energia Elétrica no Sistema Elétrico Nacional (PRODIST) Módulo 8 - Qualidade da Energia Elétrica," 2010.

[4] M. Romani, "Impactos da geração distribuída na estabilidade a grandes perturbações em sistemas de geração e transmissão de energia elétrica," 2014.

[5] N. G. Bretas and L. F. C. Alberto, Estabilidade transitória em sistema eletroenergéticos. EESC/USP, 2000.

[6] M. E. Baran and F. F. Wu, "Network reconfiguration in distribution systems for loss reduction and load balancing," IEEE Trans. Power Deliv., vol. 4, no. 2 pp. 1401-1407, Apr. 1989.

[7] L. V. L. de Abreu, "Analise do desempenho dinamico de geradores sincronos conectados em redes de distribuição de energia eletrica," 2005. 